\title{
Dechlorination of Hexachloroethane in Water Using Iron Shavings and Amended Iron Shavings: Kinetics and Pathways
}

\author{
D. L. Wu, Y. X. Liu, Z. G. Liu, and L. M. Ma \\ State Key Laboratory of Pollution Control and Resource Reuse, College of Environmental Science and Engineering, \\ Tongji University, Shanghai 200092, China
}

Correspondence should be addressed to Z. G. Liu; lzg0532@tongji.edu.cn

Received 5 March 2014; Accepted 18 May 2014; Published 30 June 2014

Academic Editor: Chaomeng Dai

Copyright (C) 2014 D. L. Wu et al. This is an open access article distributed under the Creative Commons Attribution License, which permits unrestricted use, distribution, and reproduction in any medium, provided the original work is properly cited.

In contrast to previous studies which employed zero-valent iron powder, this paper investigated reductive dechlorination of hexachloroethane (HCA) using iron shavings and bimetallic iron shavings modified with $\mathrm{Cu}, \mathrm{Ag}$, or Pd. Results clearly show that iron shavings offer superior reductive dechlorination of HCA. In addition, surface-normalized pseudo first-order dechlorination rates of $0.0073 \mathrm{~L} \cdot \mathrm{m}^{-2} \cdot \mathrm{h}^{-1}, 0.0136 \mathrm{~L} \cdot \mathrm{m}^{-2} \cdot \mathrm{h}^{-1}, 0.0189 \mathrm{~L} \cdot \mathrm{m}^{-2} \cdot \mathrm{h}^{-1}$, and $0.0084 \mathrm{~L} \cdot \mathrm{m}^{-2} \cdot \mathrm{h}^{-1}$ were observed in the presence of iron shavings $\left(\mathrm{Fe}^{0}\right)$ and the bimetallic iron shavings $\mathrm{Cu} / \mathrm{Fe}, \mathrm{Ag} / \mathrm{Fe}$, and $\mathrm{Pd} / \mathrm{Fe}$, respectively. Bimetallic iron shavings consisting of $\mathrm{Cu} / \mathrm{Fe}$ and $\mathrm{Ag} / \mathrm{Fe}$ could greatly enhance the reductive reaction rate; $\mathrm{Pd} / \mathrm{Fe}$ was used to achieve complete dechlorination of $\mathrm{HCA}$ within 5 hours. The additives of Ag and Pd shifted product distributions, and the reductive dechlorination of HCA occurred via $\beta$ reductive elimination and sequential hydrogenolysis in the presence of all iron shavings. This study consequently designed a reaction pathway diagram which reflected the reaction pathway and most prevalent dechlorination products. Iron shavings are a common byproduct of mechanical processing plants. While the purity of such Fe metals may be low, these shavings are readily available at low costs and could potentially be used in engineering applications such as contamination control technologies.

\section{Introduction}

Since zero-valent iron (ZVI) was applied to perform the reductive dechlorination of chlorinated alkanes in the early 1990s [1], the use of ZVI to treat contaminants has been an attractive research topic $[2,3]$. As a result, numerous relevant studies have been performed on such reductive transformation of contaminants including aromatic compounds [4], heavy metals $[5,6]$, radioactive pollutant [7], and azo dyes [8]. Iron media have also been investigated for remediation of nitrate in contaminated groundwater [9]. Possible mechanisms considered for contaminant reduction on iron media include (i) direct reduction at the metal surface, possibly via pitting in the oxide surface, (ii) reduction by $\mathrm{Fe}$ (II) formed in situ, and (iii) reduction by atomic hydrogen [10, 11].

In order to enhance the reactivity and functionality of ZVI, depositing the other metals such as $\mathrm{Ni}, \mathrm{Cu}, \mathrm{Pt}$, or $\mathrm{Pd}$ as a catalyst onto the iron surface leads to the synthesis of bimetallic iron particles. Fennelly and Roberts employed individual metals and several bimetals $(\mathrm{Ni} / \mathrm{Fe}, \mathrm{Cu} / \mathrm{Fe})$ to investigate the reductive degradation of 1,1,1-trichloroethane (1,1,1-TCA) [12]; this work proved that bimetals can not only boost the dechlorination reaction rate, but they can also exert a large influence on the types of final products. In addition, there have been many reports concerning the use of nanoscale ZVI and nanoscale bimetallic iron to study the reductive treatment of pollutants [13-15]. Nanoscale iron has high dechlorination reactivity but it is very costly to produce and also highly vulnerable to inactivation and aggregation.

The most relevant prior research has focused on the use of ZVI powder or nanoscale iron to investigate the reductive transformation of contaminants in groundwater. But iron powder and nanoscale-iron consist of extremely fine particles; they readily form inactive films. Iron shavings, which are a common solid waste generated in many mechanical processing plants with an abundant local supply and relatively low cost are a superior reducing agent. In actual engineering applications, iron shavings offer stable longterm performance. Ma and Zhang have already employed filler produced from iron shavings in large-scale engineering 
applications containing 910,000 kilograms of iron shavings $\left(60,000 \mathrm{~m}^{3} / \mathrm{d}\right)$, which have chiefly consisted of industrial wastewater pretreatment, and the material has been shown to improve wastewater biodegradability [16]. However, there has been no systematic research on the specific reaction processes and detailed mechanisms when iron shavings are used to perform the reductive transformation of pollutants. Works on the amended iron shavings by $\mathrm{Cu}, \mathrm{Ag}$, and $\mathrm{Pd}$ are very limited as well, particularly, the Ag/Fe bimetallic iron. One of the primary goals of this study is to fill this gap. Wüst et al. observed a combined zero- and first-order kinetic model in describing the dechlorination of TCE and cis-DCE by ZVI [17]. Arnold and Roberts adapted a modified LangmuirHinshelwood-Hougen-Watson (LHHW) kinetic model to describe iron mediated dechlorination of chlorinated ethylene and acetylene [18]. However, reported reaction rates for various chlorinated compounds are highly variable among different investigators.

The characteristics of iron shavings differed from iron powder greatly, and there has been no research reports concerning the potential reduction processes and mechanisms of chlorinated hydrocarbons by iron shavings. Furthermore, because most past research on reaction kinetics focused on the overall kinetics of removal of parent compounds, there has been limited research on the entire kinetics of final reaction products and intermediate products. This study uses iron shavings, which possess tremendous engineering application potential, as the main reducing agent, and compares the reaction performance of iron shavings and conventional iron powder. Taking hexachloroethane as the target pollutant, the reductive reactivity of iron shavings and bimetallic iron shavings was investigated in batch experiments, as well as the detailed entire reaction kinetics, reaction products, and pathways. This study might facilitate the development of iron shaving wastewater treatment techniques by providing a fullscale understanding of the mechanism that iron shavings bring about on the reductive transformation of pollutants.

\section{Experimental Section}

2.1. Materials and Reagents. The chief experimental material consisted of metallic iron shavings, which were obtained from the machine shop at Tongji University; the shavings made of $38 \mathrm{CrMoAl}$ steel, with a carbon content of approximately 0.3-0.4\%, also contained trace elements, including $\mathrm{Si}, \mathrm{Mn}$, $\mathrm{Cr}, \mathrm{Mo}$, and $\mathrm{Al}$ (detailed elemental composition is shown in Table 1). A lathe was used to cut the iron into curly shavings with a width of $0.5-1.0 \mathrm{~cm}$, length of $3-10 \mathrm{~cm}$, and thickness of $0.2 \mathrm{~mm}$. The specific surface area of the iron shavings was $0.3 \mathrm{~m}^{2} / \mathrm{g}$ (tested by application of the BrunauerEmmett-Teller (BET)); the appearance of the shavings is shown in Figure 1. The experiment used $100 \mathrm{~mL}$ reaction bottles (marked volume of $100 \mathrm{~mL}$, actual volume of roughly $120 \mathrm{~mL}$ ) to ensure that the reaction occurred in a tightly sealed vessel, and $1 \mathrm{~mL}$ gas-tight sample collectors were used to collect samples for analysis. Deionized water from MilliQ (Millipore Corp.) deoxygenated by purging with highpurity $\mathrm{N}_{2}$ was used in all experiments. The reagents of
TABLE 1: Elemental composition of iron shavings used (\%).

\begin{tabular}{lc}
\hline Elemental & Content (wt\%) \\
\hline $\mathrm{Fe}$ & $>95$ \\
$\mathrm{C}$ & $0.35 \sim 0.42$ \\
$\mathrm{Si}$ & $0.2 \sim 0.45$ \\
$\mathrm{Mn}$ & $0.3 \sim 0.6$ \\
$\mathrm{Cr}$ & $1.35 \sim 1.65$ \\
$\mathrm{Mo}$ & $0.15 \sim 0.25$ \\
$\mathrm{Al}$ & $0.70 \sim 1.10$ \\
\hline
\end{tabular}

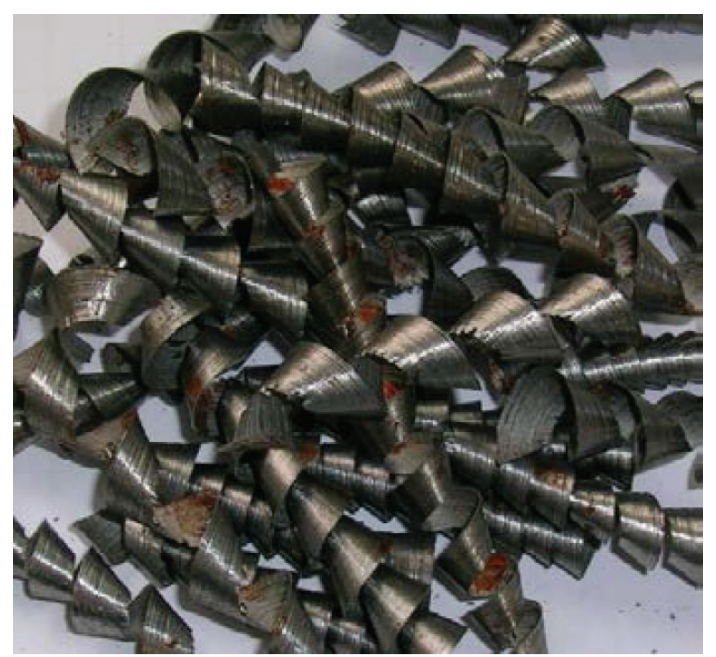

FIGURE 1: Image of the unwashed shavings (38\#CrMoAl steel).

hexachloroethane, pentachloroethane, tetrachloroethylene, trichloroethylene, and dichloroethylene were all HPLC grade and were purchased from the Sigma Company. The $\mathrm{NaOH}$, $\mathrm{NaHCO}_{3}, \mathrm{HCl}, \mathrm{CuSO}_{4}, \mathrm{AgNO}_{3}$, and $\mathrm{PdCl}_{2}$ used in this study were analytically pure and were purchased from the Sinopharm Chemical Reagent Co., Ltd. All chemicals were used as received. The purity of the iron powder was $99 \%$; it was purchased from the Shanghai Runjie Chemical Reagent Co., Ltd.

2.2. Methods. Stock solutions of hexachloroethane were prepared in methanol. $20 \mu \mathrm{L}$ of stock solution was spiked into $1000 \mathrm{~mL}$ of aqueous solution to achieve the desired initial concentration. Iron shavings were washed in $\mathrm{NaHCO}_{3}$ solution to remove any surface oil or grease and were soaked in water for several days to allow the surface to rust. The rusty iron shavings were then washed in deaerated $0.1 \mathrm{~mol} / \mathrm{L}$ hydrochloric acid $(\mathrm{HCl})$ and rinsed 5 times with deaerated water. $50 \mathrm{~g}$ of the shavings was packed into reaction bottles with marked volume of $100 \mathrm{~mL}$, and an aqueous solution of hexachloroethane with a predetermined concentration was added. The bottles were immediately sealed using Tefloncoated stoppers and crimp-sealed with aluminum foil caps to provide a better seal. The reaction bottles were placed in a water bath on a constant temperature shaking incubator, which shook at a constant rate of $180 \mathrm{r} / \mathrm{min}$. Each experiment was performed in triplicate including a set of control vials 
containing the introduced hexachloroethane solution with the same concentration as that used in the experiment but without iron, and a set of blank vials containing only the iron and deaerated Milli-Q water. At intervals, gas-tight sample collectors were used to take samples for analysis of reactants and their transformation products. Each sample was $1 \mathrm{~mL}$; the samples were then rapidly added to automatic sampling bottles containing $29 \mathrm{~mL}$ of deionized water for analysis by purge and trap-gas chromatograph. Analysis of organic carbon mass in the controls indicated that the mass varied by less than $5 \%$ over the course of a typical experiment.

Preparation of $\mathrm{Cu} / \mathrm{Fe}, \mathrm{Ag} / \mathrm{Fe}$, and $\mathrm{Pd} / \mathrm{Fe}$ bimetallic iron shavings. The bimetallic iron shavings were prepared using a chemical deposition method by soaking the iron shavings in $\mathrm{CuSO}_{4}, \mathrm{AgNO}_{3}$, and $\mathrm{PdCl}_{2}$ solutions, respectively, which involved the deposition of $0.1 \mathrm{wt} \%$ of the other metals on the surface of the iron shavings. In this method, $\mathrm{CuSO}_{4}, \mathrm{AgNO}_{3}$, and $\mathrm{PdCl}_{2}$ solutions with desired concentrations were added to reaction bottles filled with $50 \mathrm{~g}$ of iron shavings. After reaction, it is assumed that all the other metals were coated on the iron shavings to give $0.1 \% \mathrm{Cu}, \mathrm{Ag}$, and Pd by weight, respectively. These shavings after being washed were added to hexachloroethane-water solutions employing the same method as described above, and samples were taken at fixed intervals for analysis.

2.3. Analysis. Qualitative and quantitative analyses of chlorinated alkanes were performed using XPT-GC/MS (purge and trap-gas chromatography/mass spectrometry). A TEKMAR AQUAteK70 automatic sampler was used to inject samples, with a sample volume of $5 \mathrm{~mL}$. Pretreatment conditions in the purge and trap concentrator. Purge time: 11 minutes; purge temperature: room temperature $\left(25^{\circ} \mathrm{C}\right)$; purge gas flow: $40 \mathrm{~mL} / \mathrm{min}$ (high-purity $\mathrm{N}_{2}$ ). Dry purge time: $1 \mathrm{~min}$; preheating temperature: $245^{\circ} \mathrm{C}$; sample inject temperature: $180^{\circ} \mathrm{C}$; furnace temperature: $150^{\circ} \mathrm{C}$; transmission line temperature: $150^{\circ} \mathrm{C}$. GC/MS analytical conditions: US Thermal GC/MS multipurpose instrument equipped with HP-5 capillary tube column (inner diameter: $0.25 \mathrm{~mm}$, liquid film thickness: $0.25 \mu \mathrm{m}$ ); length: $30 \mathrm{~m}$; carrier gas: high-purity $\mathrm{He}$, flow rate: $1.0 \mathrm{~mL} / \mathrm{min}$. The temperature program was initiated at a temperature of $35^{\circ} \mathrm{C}$ for 5 minutes, heating rate: $25^{\circ} \mathrm{C} / \mathrm{min}$, and final temperature: $200^{\circ} \mathrm{C}$ held for 1 minute. Sampler temperature: $200^{\circ} \mathrm{C}$, ions source temperature: $250^{\circ} \mathrm{C}$; MS transmission line temperature: $250^{\circ} \mathrm{C}$. The sample was automatically injected with a split ratio of $10: 1$.

\section{Results and Discussion}

3.1. Reductive Dechlorination of HCA by Various Iron Shavings. When investigating the reductive dechlorination reaction rate of HCA in presence of various iron shavings, the study focused on the effect of iron powder $\left(\mathrm{Fe}^{0}\right)$, iron shavings $\left(\mathrm{Fe}^{0}\right)$, and bimetallic iron shavings $(\mathrm{Cu} / \mathrm{Fe}, \mathrm{Ag} / \mathrm{Fe}, \mathrm{Pd} / \mathrm{Fe})$ on the rate of reductive dechlorination of HCA. Because the specific surface area of iron powder is $5.4 \mathrm{~m}^{2} / \mathrm{g}$, while that of iron shavings is $0.3 \mathrm{~m}^{2} / \mathrm{g}$, in order to ensure that the iron powder and iron shavings in reactor had the same surface

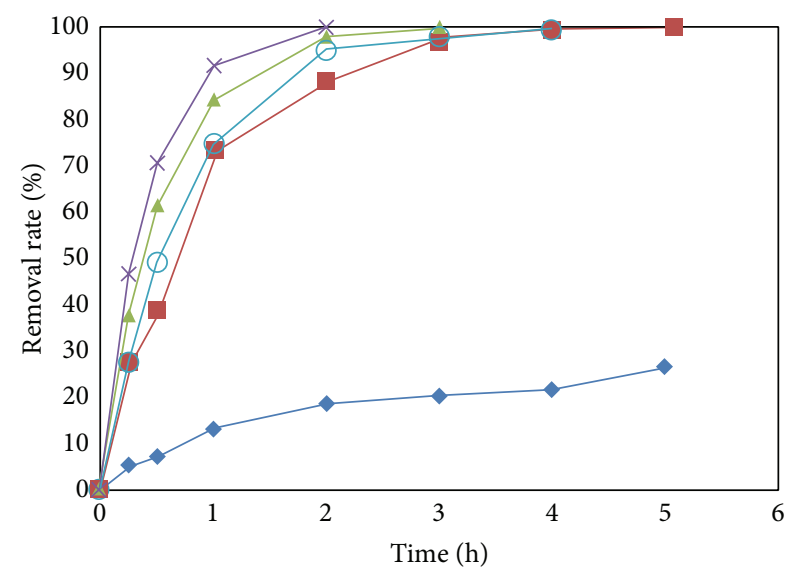

FIGURE 2: Removal rate of HCA obtained with various iron shavings. Initial concentration of HCA was $60 \mu \mathrm{mol} \cdot \mathrm{L}^{-1}$. ( $\left.\bullet\right) \mathrm{Fe}^{0}$ (powder), (ロ) $\mathrm{Fe}^{0}$ (shavings), (O) $\mathrm{Pd} / \mathrm{Fe}(0.1 \mathrm{wt} \%),(\boldsymbol{\Delta}) \mathrm{Cu} / \mathrm{Fe}(0.1 \mathrm{wt} \%),(\times)$ $\mathrm{Ag} / \mathrm{Fe}(0.1 \mathrm{wt} \%)$.

area, $2.78 \mathrm{~g}$ of iron powder was added to the bottle. As shown in Figure 2, because HCA is highly chlorinated, it readily gave rise to reductive dechlorination by iron, and relatively high reaction rates were observed in all of the iron shavings system. However, it is clearly demonstrated that HCA removal rates observed in the presence of iron shavings are much more than those obtained in the presence of iron powder. This implies that, insofar as the specific surface area of the iron is the same, iron shavings possess better reductive activity than iron powders. The primary mechanism of organic chloride compound dechlorination is thought to be an electron transfer from ZVI to the chloride organic compound $[1,19]$. Thus, the electron transfer at the iron's surface is certainly a probable process for HCA dechlorination in this system and is assumed to be the reaction mechanism in this paper. Presumably, many elementals that also consist of iron shavings can serve as the cathode to accelerate electron transfer from iron to organics and lead to the improvement of dechlorination reactions.

Identification of reaction products indicated that the variety of bimetallic iron shavings could shift the product distributions. Figures 3-6 showed the concentration of different substances as a function of time during reductive dechlorination of HCA. The initial HCA concentration was $50 \mu \mathrm{mol} \cdot \mathrm{L}^{-1}$. HCA that underwent reductive dechlorination at a very fast rate was observed in the $\mathrm{Fe}^{0}$ (shavings) reduction system. The HCA removal rate reached $90 \%$ after $2 \mathrm{~h}$ of reaction time, and the chief reaction product was perchloroethylene (PCE). PCE underwent an extremely slow reductive dechlorination reaction in the presence of $\mathrm{Fe}^{0}$ alone, and almost no dechlorination products of PCE were observed within $5 \mathrm{~h}$. It can be seen from Figure 4 that the HCA reacted at an even faster rate in the $\mathrm{Cu} / \mathrm{Fe}$ reduction system when compared with the $\mathrm{Fe}^{0}$ alone, and the HCA removal rate reached $80 \%$ within $0.5 \mathrm{~h}$. As before, the chief reaction product was also PCE. Because PCE underwent reductive dechlorination at an extremely slow rate in the $\mathrm{Cu} / \mathrm{Fe}$ system, the PCE did not continue to undergo reductive dechlorination, forming 


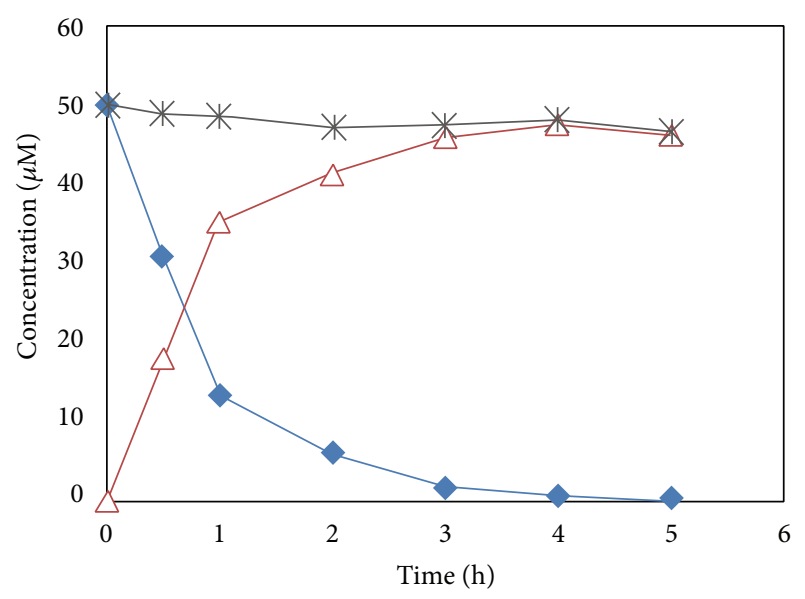

FIGURE 3: Dechlorination of HCA obtained with iron shavings alone. Initial concentration of HCA was $50 \mu \mathrm{mol} \cdot \mathrm{L}^{-1}$ and dosage of iron shavings was $500 \mathrm{~g} \cdot \mathrm{L}^{-1}$. $(\diamond) \mathrm{HCA},(\triangle) \mathrm{PCE},(*)$ mass balance (control).

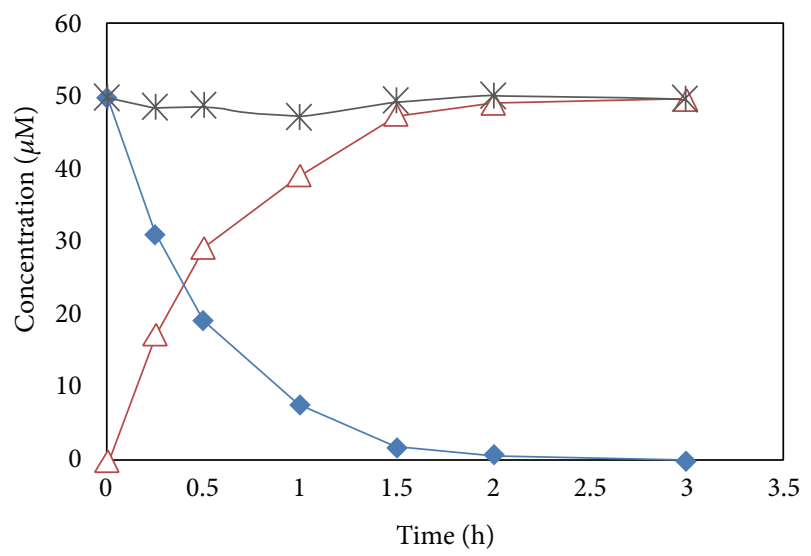

FIGURE 4: Dechlorination of HCA obtained with $\mathrm{Cu} / \mathrm{Fe}(0.1 \mathrm{wt} \%)$. Initial concentration of $\mathrm{HCA}$ was $50 \mu \mathrm{mol} \cdot \mathrm{L}^{-1}$ and dosage of amended iron shavings was $500 \mathrm{~g} \cdot \mathrm{L}^{-1}$. $(\bullet) \mathrm{HCA},(\triangle) \mathrm{PCE},(*)$ mass balance (control).

other products within the time allotted for the experiment. However, the removal rate of HCA was found to be faster by $\mathrm{Cu} / \mathrm{Fe}$ than by $\mathrm{Fe}^{0}$ alone.

Figure 5 clearly reveals that HCA is reduced even faster in the $\mathrm{Ag} / \mathrm{Fe}$ system than in the $\mathrm{Fe}^{0}$ and $\mathrm{Cu} / \mathrm{Fe}$ reduction systems. The products are more complex, because the chief reductive dechlorination product, $\mathrm{PCE}$, can continue to undergo reductive dechlorination to form products such as TCE and DCE. The chief reduction products of a dilute HCA solution with $\mathrm{Ag} / \mathrm{Fe}$ consist of PCE, TCE, and DCE. In addition, since DCE is ordinarily composed of the two isomers-cis-DCE and trans-DCE-HCA, it has a relatively complex reaction pathway. The addition of $\mathrm{Ag}$ can accelerate the dechlorination rate of HCA and PCE significantly, achieving nearly $100 \%$ removal rate within $2 \mathrm{~h}$ and $6 \mathrm{~h}$, respectively, at a near neutral $\mathrm{pH}$. Previous researches have shown that in

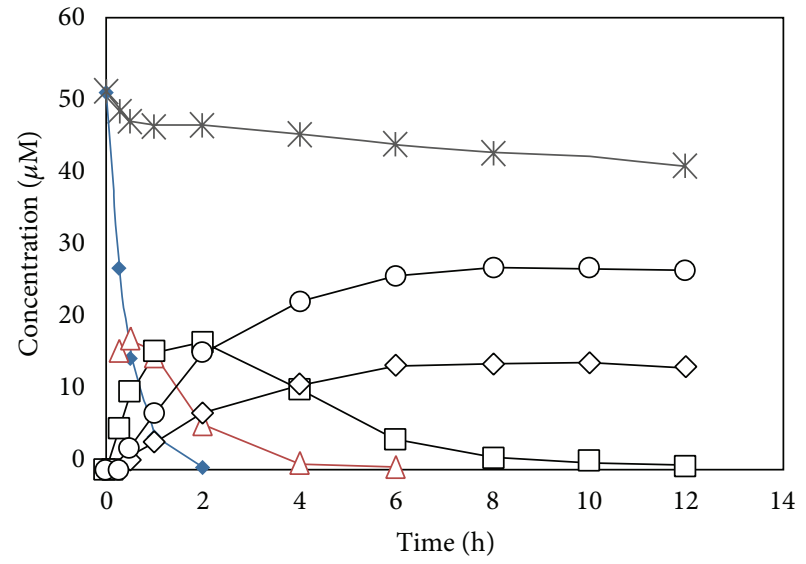

FIGURE 5: Dechlorination of HCA obtained with $\mathrm{Ag} / \mathrm{Fe}(0.1 \mathrm{wt} \%)$. Initial concentration of $\mathrm{HCA}$ was $50 \mu \mathrm{mol} \cdot \mathrm{L}^{-1}$ and dosage of amended iron shavings was $500 \mathrm{~g} \cdot \mathrm{L}^{-1} .(\diamond) \mathrm{HCA},(\triangle)$ PCE, ( $\left.\square\right)$ TCE, $(\diamond)$ trans-DCE, $(\bigcirc)$ cis-DCE, $(*)$ mass balance (control).

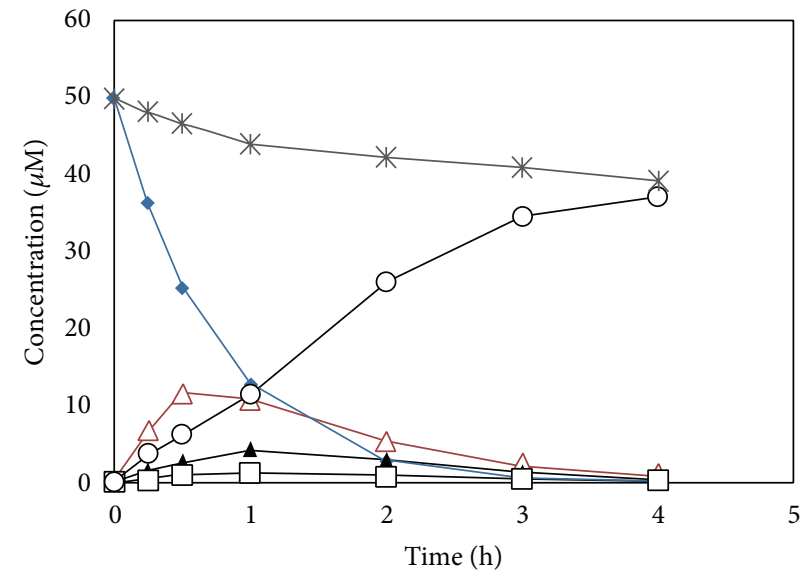

FIgURE 6: Dechlorination of HCA obtained with Pd/Fe (0.1 wt\%). Initial concentration of $\mathrm{HCA}$ was $50 \mu \mathrm{mol} \cdot \mathrm{L}^{-1}$ and dosage of amended iron shavings was $500 \mathrm{~g} \cdot \mathrm{L}^{-1} .(\diamond) \mathrm{HCA},(\triangle) \mathrm{PCE},(\boldsymbol{\Delta}) \mathrm{TCE}$, () DCE, (O) $\mathrm{C}_{2} \mathrm{H}_{4},(*)$ mass balance (control).

bimetallic iron system, other metals can serve as a cathode to accelerate electron transfer from iron [20].

The dechlorination of HCA by $\mathrm{Pd} / \mathrm{Fe}$ was shown in Figure 6. Unlike the $\mathrm{Fe}$ alone, $\mathrm{Cu} / \mathrm{Fe}$, and $\mathrm{Ag} / \mathrm{Fe}$ materials, the chief reduction product of HCA with $\mathrm{Pd} / \mathrm{Fe}$ is ethylene, and the chief intermediate products are PCE and TCE. This indicates that the dechlorination of HCA first occurs $\beta$ reductive elimination forming PCE, and then quickly undergoes sequential hydrogenolysis to TCE, and TCE is in turn rapidly dechlorinated to ethylene. Compared with the $\mathrm{Fe}^{0}, \mathrm{Cu} / \mathrm{Fe}$, and $\mathrm{Ag} / \mathrm{Fe}, \mathrm{HCA}$ is even more thoroughly dechlorinated in the $\mathrm{Pd} / \mathrm{Fe}$ catalytic reduction system, and the final product is the chlorine-free substance, ethylene. Research literature indicates that $\mathrm{Pd}$ is an excellent hydrogenation catalyst and can achieve the complete reductive dechlorination of chlorinated organic compounds without producing chlorinecontaining compounds. The $\mathrm{H}$ generated by iron corrosion 
can be catalyzed on the Pd surface to produce atomic hydrogen $\left(\mathrm{H}^{*}\right)$ for the chlorinated compounds dechlorination via Pd-catalyzed hydrodechlorination reactions [21]. The use of palladium-plated iron shavings in this research similarly caused HCA to undergo a fully dechlorinated reaction yielding the final product, ethylene. Bimetallic irons are frequently more reactive towards organohalides than unamended iron and can also alter product distributions. Cwiertny et al. demonstrated that not all additives enhanced rates of 1,1,1-trichloroethane (1,1,1-TCA) reduction nor was there any clear periodic trend in the observed reactivity [22]. And results suggested that absorbed atomic hydrogen, rather than galvanic corrosion, is responsible for the enhanced reactivity of bimetallic reductants.

3.2. Reaction Kinetics. The reduction of chlorinated organic compounds by the iron shavings is a typical solid-liquid interface reaction and has the following main reaction formula:

$$
\mathrm{RClx}+\mathrm{Fe}^{0}+\mathrm{H}_{2} \mathrm{O} \longrightarrow \mathrm{RHCl}_{x-1}+\mathrm{Fe}^{2+}+\mathrm{OH}^{-}+\mathrm{Cl}^{-}
$$

In the reaction process, solid $\mathrm{Fe}^{0}$ is always in excess. The vast majority of surface reactions can be described using the Langmuir-Hinshelwood kinetics model. When the reaction takes place in a dilute solution of the reactants, the reaction rate equation can be expressed as

$$
-\frac{d C}{d t}=k b C=K_{\mathrm{obs}} C .
$$

In this equation, $K_{\mathrm{obs}}$ is the observed reaction rate constant, which is the experimental reaction rate constant, and $C$ represents the concentration of reactants. It is well established that the pseudo first-order kinetics could be applied in the reductive dechlorination of chlorinated organics by ZVI and bimetallic iron $[1,23]$. While a dilute solution of HCA will quickly undergo a reductive dechlorination reaction by any of the iron shavings. The first step in the reductive dechlorination of HCA is $\beta$ reductive elimination, which yields PCE. Unlike $\mathrm{Fe}^{0}, \mathrm{Cu} / \mathrm{Fe}$, or $\mathrm{Pd} / \mathrm{Fe}$, the reductive dechlorination of $\mathrm{HCA}$ by $\mathrm{Ag} / \mathrm{Fe}$ is consequently a reaction network comprising of both one-way continuous reactions and parallel reactions as in Figure 7.

We can write the following reaction rate equations for each species based on the above pathway:

$$
\begin{aligned}
\frac{d[\mathrm{HCA}]}{d t} & =-k_{1}[\mathrm{HCA}], \\
\frac{d[\mathrm{PCE}]}{d t} & =k_{1}[\mathrm{HCA}]-k_{2}[\mathrm{PCE}], \\
\frac{d[\mathrm{TCE}]}{d t} & =k_{2}[\mathrm{PCE}]-\left(k_{3}+k_{4}\right)[\mathrm{TCE}], \\
\frac{d[\text { cis }-\mathrm{DCE}]}{d t} & =k_{3}[\mathrm{TCE}], \\
\frac{d[\text { trans }-\mathrm{DCE}]}{d t} & =k_{4}[\mathrm{TCE}] .
\end{aligned}
$$

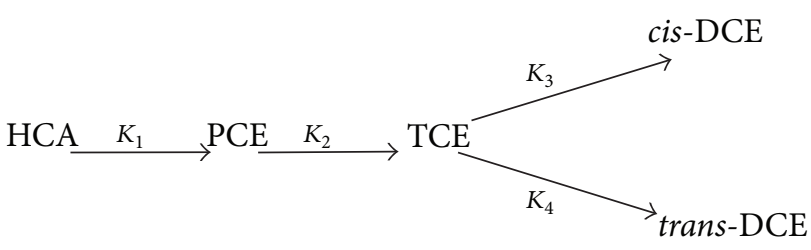

Figure 7: Reaction pathways for HCA reduction by Ag/Fe.

Solving (3), (4), and (5) yields

$$
\begin{gathered}
{[\mathrm{HCA}]=[\mathrm{HCA}]_{0} e^{-k_{1} t},} \\
{[\mathrm{PCE}]=\frac{k_{1}}{k_{2}-k_{1}}\left(e^{-k_{1} t}-e^{-k_{2} t}\right)[\mathrm{HCA}]_{0},} \\
{[\mathrm{TCE}]=k_{1} k_{2}[\mathrm{HCA}]_{0}} \\
\times\left\{\frac{e^{-k_{1} t}}{\left(k_{1}-k_{2}\right)\left(k_{1}-k_{3}-k_{4}\right)}\right. \\
+\frac{e^{-k_{2} t}}{\left(k_{2}-k_{1}\right)\left(k_{2}-k_{3}-k_{4}\right)} \\
\left.+\frac{e^{-\left(k_{3}+k_{4}\right) t}}{\left(k_{3}+k_{4}-k_{1}\right)\left(k_{3}+k_{4}-k_{2}\right)}\right\} .
\end{gathered}
$$

Zhou et al. have established the entire kinetics of 2,4,6trichlorophenol by $\mathrm{Pd} / \mathrm{Fe}$ including parent compounds and daughter compounds [21]. In accordance with data from dechlorination experiments using individual species of HCA, PCE, and TCE, we can derive that $K_{1}=2.842 \mathrm{~h}^{-1}, K_{2}=$ $1.251 \mathrm{~h}^{-1}$, and $K_{3}+K_{4}=0.463 \mathrm{~h}^{-1}$. Following product analysis, it was found that in this experiment the mole ratio of the products cis-DCE and trans-DCE was 2.1, and therefore $K_{3} / K_{4}=2.1$. It can then be calculated that $K_{3}=0.149 \mathrm{~h}^{-1}$ and $K_{4}=0.314 \mathrm{~h}^{-1}$. When $[\mathrm{HCA}]_{0}=50 \mu \mathrm{mol} \cdot \mathrm{L}^{-1}$ and all $K$ values are substituted into the foregoing reaction kinetics equations, one obtains

$$
\begin{aligned}
{[\mathrm{HCA}] } & =50 e^{-2.842 t}, \\
{[\mathrm{PCE}] } & =89\left(e^{-1.251 t}-e^{-2.842 t}\right), \\
{[\mathrm{TCE}] } & =47 e^{-2.842 t}-142 e^{-1.251 t}+95 e^{-0.463 t} .
\end{aligned}
$$

According to the mass balance,

$$
\begin{aligned}
{[\mathrm{HCA}]_{0}=} & {[\mathrm{HCA}]+[\mathrm{PCE}]+[\mathrm{TCE}] } \\
& +[\text { cis-DCE }]+[\text { trans }-\mathrm{DCE}] .
\end{aligned}
$$

One obtains

$$
\begin{gathered}
{[\text { trans }-\mathrm{DCE}]=0.323\left(50-8 e^{-2.842 t}+53 e^{-1.251 t}\right.} \\
\left.-95 e^{-0.463 t}\right) \\
{[\text { cis-DCE }]=0.677\left(50-8 e^{-2.842 t}+53 e^{-1.251 t}\right.} \\
\left.-95 e^{-0.463 t}\right) .
\end{gathered}
$$




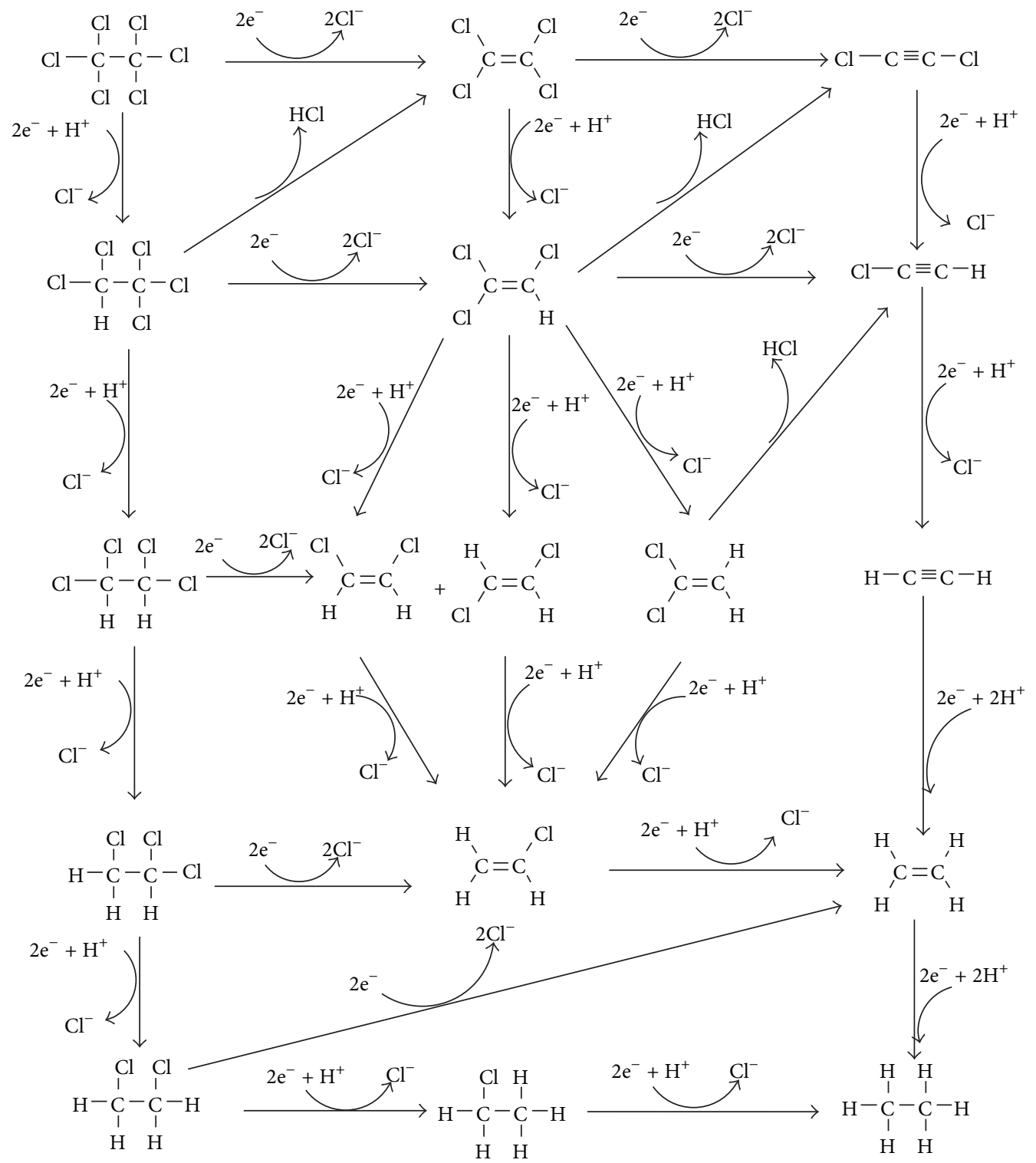

FIGURE 8: Proposed pathway for the dechlorination of HCA by iron shavings and amended iron shavings.

As a result, the entire reaction kinetics of the reductive dechlorination of an HCA solution with an initial concentration of $50 \mu \mathrm{mol} \cdot \mathrm{L}^{-1}$ in the presence of $\mathrm{Ag} / \mathrm{Fe}$ can be expressed using the foregoing equations, in this way the curve expressed by the kinetics equation fits the experimental data. Similarly, the kinetics of HCA reduction by various iron shavings could be calculated according to reaction pathways. All the kinetic equations were summarized in Table 2.

After normalization of the surface of the iron shavings, the rate constants $K_{S A}$ are $0.0073 \mathrm{~L} \cdot \mathrm{m}^{-2} \cdot \mathrm{h}^{-1}$, $0.0136 \mathrm{~L} \cdot \mathrm{m}^{-2} \cdot \mathrm{h}^{-1}, \quad 0.0189 \mathrm{~L} \cdot \mathrm{m}^{-2} \cdot \mathrm{h}^{-1}$, and $0.0084 \mathrm{~L} \cdot \mathrm{m}^{-2} \cdot \mathrm{h}^{-1}$, respectively. It was found that the $\mathrm{Ag} / \mathrm{Fe}$ and $\mathrm{Cu} / \mathrm{Fe}$ could enhance reductive dechlorination of HCA obviously. The $\mathrm{Cu} / \mathrm{Fe}$ can speed up the reaction rate nearly twofold, and the $\mathrm{Ag} / \mathrm{Fe}$ can increase it about 3 times compared to iron shavings alone. While the $\mathrm{Pd} / \mathrm{Fe}$ catalytic material has relatively little effect on the HCA removal rate, however, it can make HCA dechlorination to nonchlorinated products due to Pd as an excellent hydrogenation catalyst.

3.3. Intermediate Products and Reaction Pathways. Fennelly and Roberts observed different 1,1,1-trichloroethane (1,1,1TCA) product distributions in $\mathrm{Ni} / \mathrm{Fe}$ and $\mathrm{Cu} / \mathrm{Fe}$ systems [12]. In order to perform a thorough evaluation of the products resulting from the reductive dechlorination of HCA, a highconcentration aqueous solution of HCA was prepared and the GC/MS system was used. The results of this experiment clearly indicated that, apart from transformation to PCE via $\beta$ reductive elimination, $\mathrm{HCA}$ can also undergo hydrogenolysis to produce pentachloroethane (PCA) and tetrachloroethane (TeCA) and then trichloroethane (TCA) and dichloroethane (DCA). Furthermore, PCE also undergoes further dechlorination in the $\mathrm{Ag} / \mathrm{Fe}$ and $\mathrm{Pd} / \mathrm{Fe}$ reduction systems via hydrogenolysis yielding other products such 


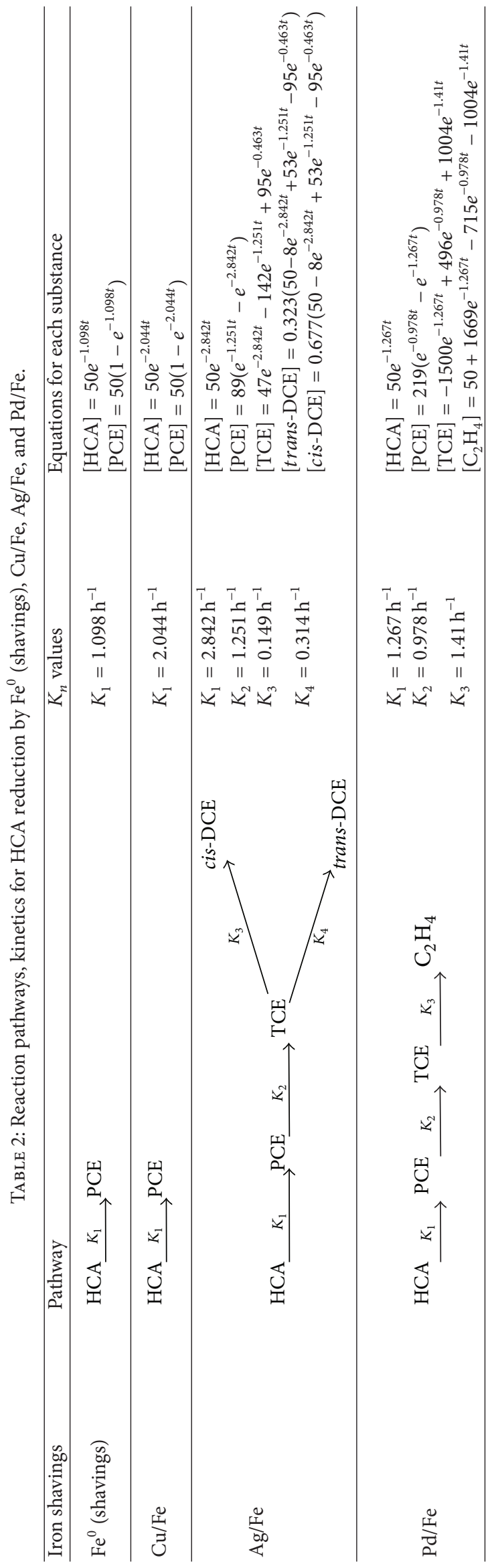


as trichloroethylene (TCE), dichloroethylene (DCE), vinyl chloride (VC), and ethylene. The reduction of PCE by $\beta$-elimination produces dichloroacetylene (DCAc), which can be further reduced to chloroacetylene (CAc) and then acetylene [24]. Reduction products are consequently highly dependent on the bimetallic materials.

In $\mathrm{Ag} / \mathrm{Fe}$ reduction systems, as many as 10 species may be presented, including some products of side reactions. Determination of how these dechlorination products are generated is an extremely significant issue in research on the reaction pathway and reaction mechanism for the reductive dechlorination of HCA by various iron shavings. The proposed degradation pathways of HCA with various iron shavings based on the detected dechlorination products and the theoretical derivation were shown in Figure 8.

Results suggest that the pathway of the reductive dechlorination of HCA by iron shavings was found to be predominantly reductive $\beta$ elimination. Apart from this, hydrogenolysis and dehydrochlorination reactions also occur. Previous research showed that the chemical degradation of chlorinated hydrocarbons also progressed with a stepwise dehalogenation mechanism [1]. Reductive $\beta$ elimination has been shown to be a preferential pathway for compounds possessing $\alpha$, $\beta$-pairs of chlorine atoms $[25,26]$, while hydrogenolysis or reductive $\alpha$ elimination is the primary transformation pathway for compounds possessing only $\alpha$-chlorines [12, 27]. In addition, dehydrohalogenation becomes important under basic conditions [28].

\section{Conclusions}

The presented study gave insight into the entire dechlorination kinetics and dechlorination pathways of HCA by iron shavings and amended iron shavings. Iron shaving is a more effective reducing agent than traditional iron powder that is used in early research for dechlorination of HCA in water. The deposition of $\mathrm{Cu}, \mathrm{Ag}$, and $\mathrm{Pd}$ on the surface of iron shavings was found to significantly increase the rate of HCA reduction, $\mathrm{Ag} / \mathrm{Fe}$ shavings increased the HCA reduction rate nearly threefold compared to iron shavings alone, and $\mathrm{Pd} / \mathrm{Fe}$ shavings can promote the complete reductive dechlorination of HCA within $4 \mathrm{~h}$, yielding products containing no chlorine. The dechlorination of HCA by all types of iron shavings followed pseudo first-order reaction kinetics. The pathway of reductive dechlorination of HCA predominantly consists of $\beta$ reductive elimination, and hydrogenolysis and dehydrochlorination reactions also occur. Iron shavings are widely available inexpensive waste products and possess good reactivity and longevity usage in treatment of wastewater, and they can be readily used in engineering applications.

\section{Conflict of Interests}

The authors declare that there is no conflict of interests regarding the publication of this paper.

\section{Acknowledgments}

This work was financially supported by the Natural Science Foundation of China (Grant nos. 41172210, 50808136), the Fundamental Research Funds for the Central Universities (no. 0400219188), and the National Key Technology R\&D Program (no. 2013BAC01B01).

\section{References}

[1] L. J. Matheson and P. G. Tratnyek, "Reductive dehalogenation of chlorinated methanes by iron metal," Environmental Science and Technology, vol. 28, no. 12, pp. 2045-2053, 1994.

[2] D. L. Wu, H. W. Wang, J. H. Fan, and L. M. Ma, "Catalytic reduction of $\mathrm{CCl} 4$ in water by $\mathrm{Fe} 0$ and amended Fe0," Huanjing Kexue/Environmental Science, vol. 29, no. 12, pp. 3433-3438, 2008.

[3] X. Zhang, B. Deng, J. Guo, Y. Wang, and Y. Lan, "Ligand-assisted degradation of carbon tetrachloride by microscale zero-valent iron," Journal of Environmental Management, vol. 92, no. 4, pp. 1328-1333, 2011.

[4] B. Jafarpour, P. T. Imhoff, and P. C. Chiu, "Quantification and modelling of 2,4-dinitrotoluene reduction with high-purity and cast iron," Journal of Contaminant Hydrology, vol. 76, no. 1-2, pp. 87-107, 2005.

[5] M. Gheju, "Hexavalent chromium reduction with zero-valent iron (ZVI) in aquatic systems," Water, Air, and Soil Pollution, vol. 222, no. 1-4, pp. 103-148, 2011.

[6] N. Melitas, J. Wang, M. Conklin, P. O'Day, and J. Farrell, "Understanding soluble arsenate removal kinetics by zerovalent iron media," Environmental Science and Technology, vol. 36, no. 9, pp. 2074-2081, 2002.

[7] C. Noubactep, K. B. D. Btatkeu, and J. B. Tchatchueng, "Impact of $\mathrm{MnO}_{2}$ on the efficiency of metallic iron for the removal of dissolved $\mathrm{Cr}^{V I}, \mathrm{Cu}^{I I}, \mathrm{Mo}^{V I}, \mathrm{~S}^{b V}, \mathrm{U}^{V I}$ and $\mathrm{Zn}^{I I}$," Chemical Engineering Journal, vol. 178, pp. 78-84, 2011.

[8] J. A. Mielczarski, G. M. Atenas, and E. Mielczarski, "Role of iron surface oxidation layers in decomposition of azo-dye water pollutants in weak acidic solutions," Applied Catalysis B: Environmental, vol. 56, no. 4, pp. 289-303, 2005.

[9] S. Mossa Hosseini, B. Ataie-Ashtiani, and M. Kholghi, "Nitrate reduction by nano-Fe/Cu particles in packed column," Desalination, vol. 276, no. 1-3, pp. 214-221, 2011.

[10] J. Klausen, S. P. Trober, S. B. Haderlein, and R. P. Schwarzenbach, "Reduction of substituted nitrobenzenes by $\mathrm{Fe}(\mathrm{II})$ in aqueous mineral suspensions," Environmental Science and Technology, vol. 29, no. 9, pp. 2396-2404, 1995.

[11] A. M. Moore, C. H. De Leon, and T. M. Young, "Rate and extent of aqueous perchlorate removal by iron surfaces," Environmental Science and Technology, vol. 37, no. 14, pp. 3189-3198, 2003.

[12] J. P. Fennelly and A. L. Roberts, "Reaction of 1,1,1-trichloroethane with zero-valent metals and bimetallic reductantsEnvironmental Science and Technology," vol. 32, pp. 1980-1988, 1998.

[13] C. B. Wang and W. X. Zhang, "Synthesizing nanoscale iron particles for rapid and complete dechlorination of TCE and PCBs," Environmental Science and Technology, vol. 31, no. 7, pp. 2154-2156, 1997.

[14] J. Zhang, Z. Hao, Z. Zhang, Y. Yang, and X. Xu, "Kinetics of nitrate reductive denitrification by nanoscale zero-valent iron," 
Process Safety and Environmental Protection, vol. 88, no. 6, pp. 439-445, 2010.

[15] Y. H. Shih, C. Y. Hsu, and Y. F. Su, "Reduction of hexachlorobenzene by nanoscale zero-valent iron: kinetics, $\mathrm{pH}$ effect, and degradation mechanism," Separation and Purification Technology, vol. 76, no. 3, pp. 268-274, 2011.

[16] L. Ma and W. X. Zhang, "Enhanced biological treatment of industrial wastewater with bimetallic zero-valent iron," Environmental Science and Technology, vol. 42, no. 15, pp. 5384-5389, 2008.

[17] W. F. Wüst, R. Köber, O. Schlicker, and A. Dahmke, “Combined zero- and first-order kinetic model of the degradation of tce and cis-DCE with commercial iron," Environmental Science and Technology, vol. 33, no. 23, pp. 4304-4309, 1999.

[18] W. A. Arnold and A. L. Roberts, "Pathways and kinetics of chlorinated ethylene and chlorinated acetylene reaction with $\mathrm{Fe}(0)$ particles," Environmental Science and Technology, vol. 34, no. 9, pp. 1794-1805, 2000.

[19] Y. H. Shih, Y. C. Chen, M. Y. Chen, Y. T. Tai, and C. P. Tso, "Dechlorination of hexachlorobenzene by using nanoscale $\mathrm{Fe}$ and nanoscale $\mathrm{Pd} / \mathrm{Fe}$ bimetallic particles," Colloids and Surfaces A, vol. 332, no. 2-3, pp. 84-89, 2009.

[20] D. W. Elliott and W. X. Zhang, "Field assessment of nanoscale bimetallic particles for groundwater treatment," Environmental Science and Technology, vol. 35, no. 24, pp. 4922-4926, 2001.

[21] T. Zhou, Y. Li, and T. T. Lim, "Catalytic hydrodechlorination of chlorophenols by Pd/Fe nanoparticles: comparisons with other bimetallic systems, kinetics and mechanism," Separation and Purification Technology, vol. 76, no. 2, pp. 206-214, 2010.

[22] D. M. Cwiertny, S. J. Bransfield, K. J. T. Livi, D. H. Fairbrother, and A. L. Roberts, "Exploring the influence of granular iron additives on 1,1,1-trichloroethane reduction," Environmental Science and Technology, vol. 40, no. 21, pp. 6837-6843, 2006.

[23] H. Song and E. R. Carraway, "Reduction of chlorinated ethanes by nanosized zero-valent iron: kinetics, pathways, and effects of reaction conditions," Environmental Science and Technology, vol. 39, no. 16, pp. 6237-6245, 2005.

[24] W. A. Arnold and A. L. Roberts, "Erratum: Pathways of chlorinated ethylene and chlorinated acetylene reaction with Zn(0)," Environmental Science and Technology, vol. 32, no. 19, pp. 3017-3025, 1998.

[25] W. A. Arnold, W. P. Ball, and A. L. Roberts, "Polychlorinated ethane reaction with zero-valent zinc: pathways and rate control," Journal of Contaminant Hydrology, vol. 40, no. 2, pp. 183200, 1999.

[26] E. C. Butler and K. F. Hayes, "Kinetics of the transformation of halogenated aliphatic compounds by iiron sulfide," Environmental Science and Technology, vol. 34, no. 3, pp. 422-429, 2000.

[27] W. A. Arnold, P. Winget, and C. J. Cramer, "Reductive dechlorination of 1,1,2,2-tetrachloroethane," Environmental Science and Technology, vol. 36, no. 16, pp. 3536-3541, 2002.

[28] P. M. Jeffers, L. M. Ward, L. M. Woytowitch, and N. L. Wolfe, "Homogeneous hydrolysis rate constants for selected chlorinated methanes, ethanes, ethenes, and propanes," Environmental Science and Technology, vol. 23, no. 8, pp. 965-969, 1989. 

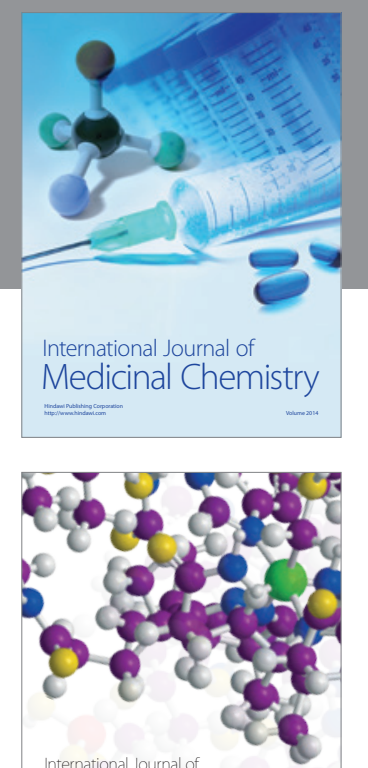

\section{Carbohydrate} Chemistry

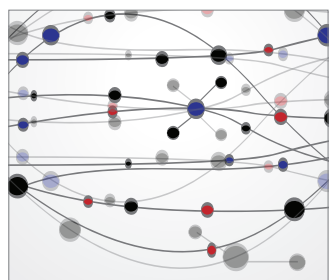

The Scientific World Journal
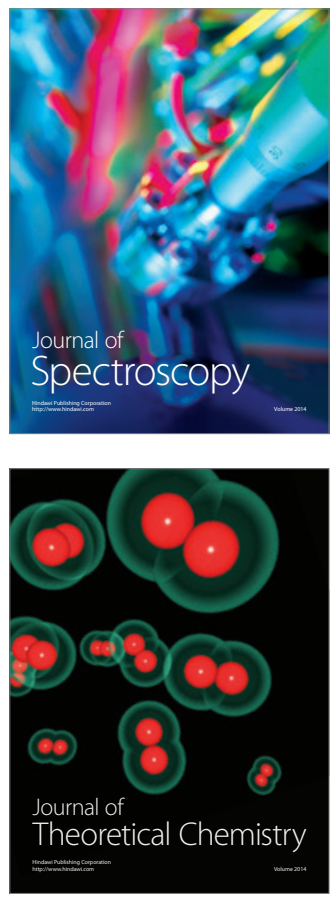
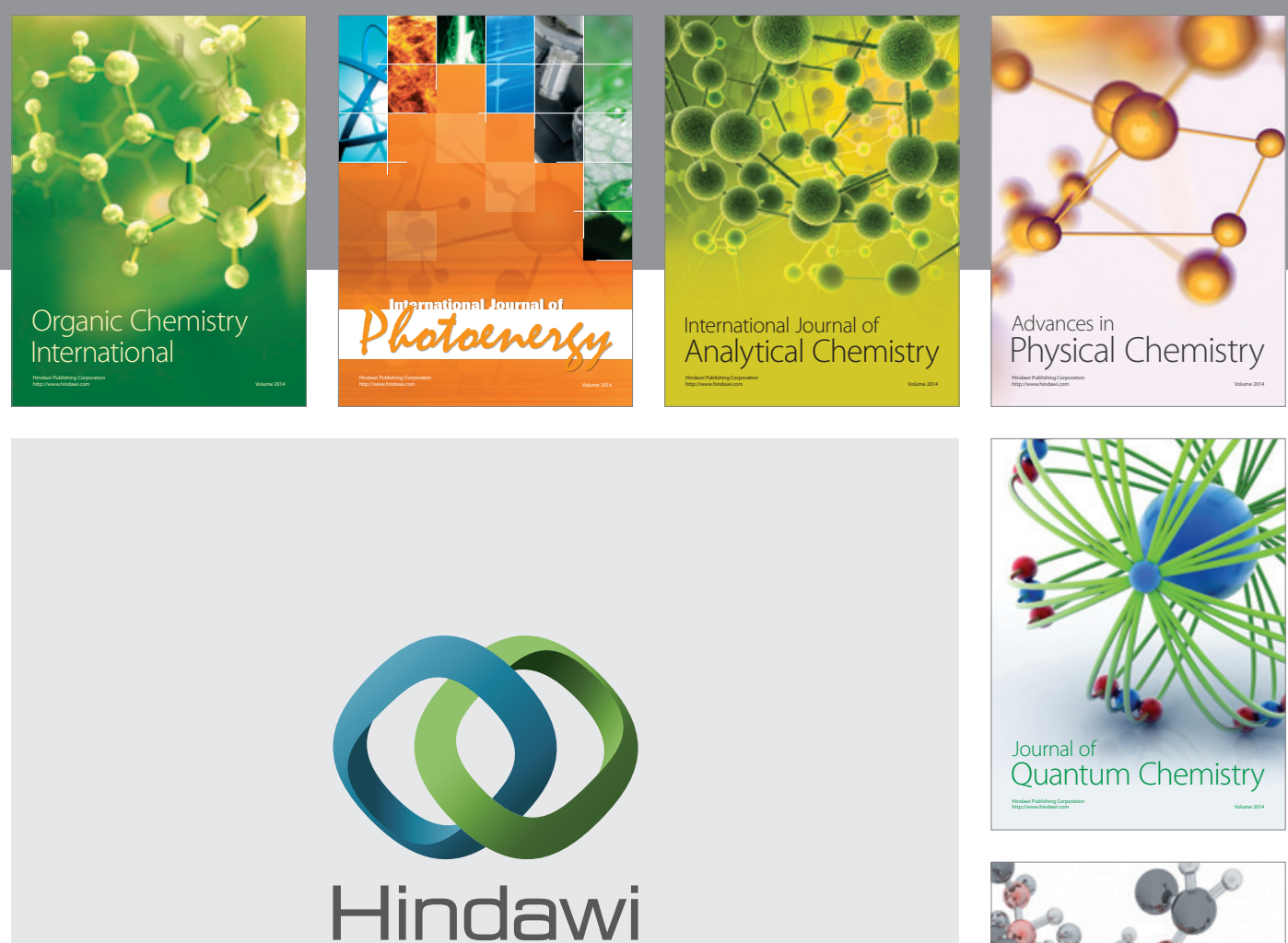

Submit your manuscripts at

http://www.hindawi.com

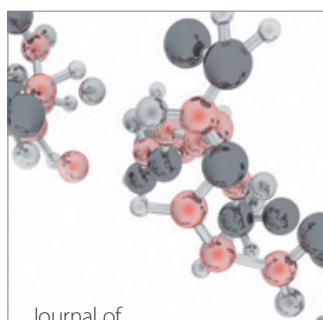

Analytical Methods

in Chemistry

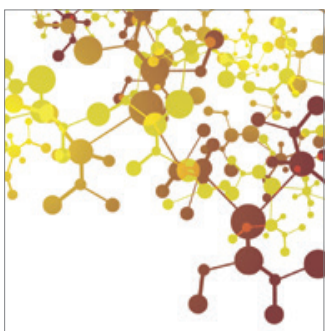

Journal of

Applied Chemistry

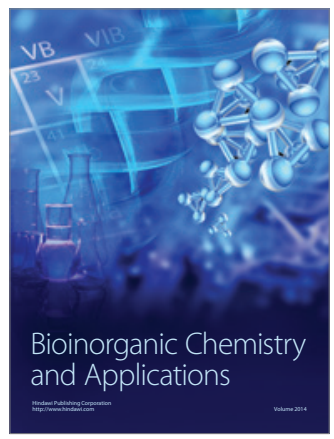

Inorganic Chemistry
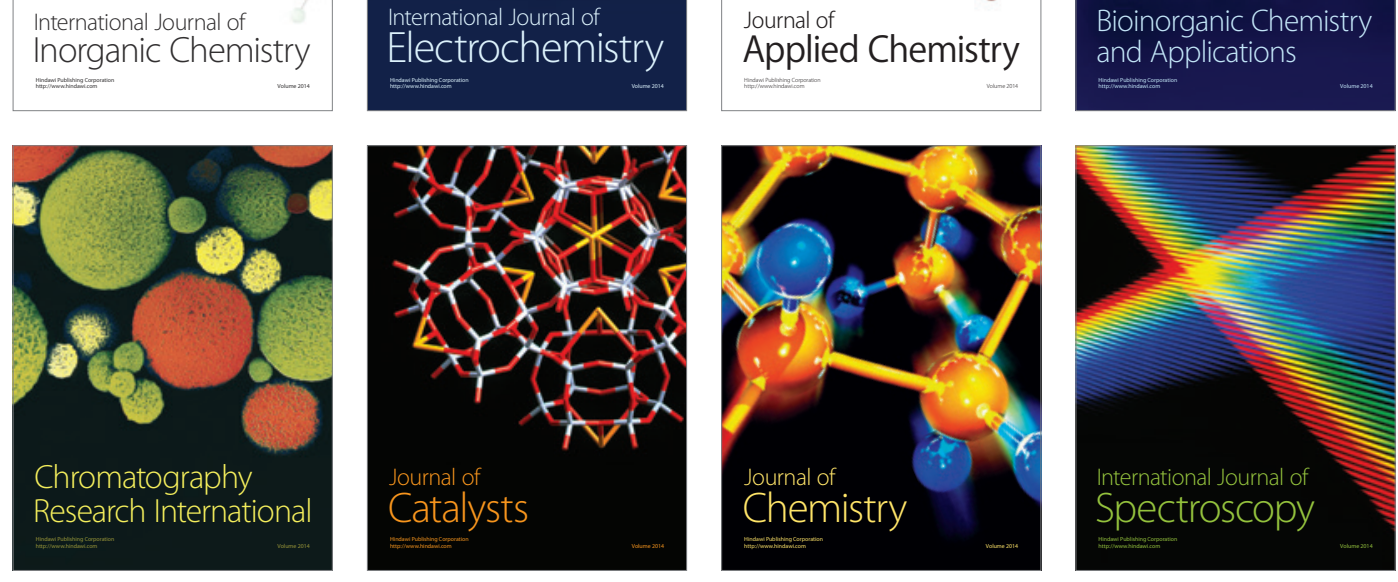